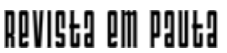

\section{Instituto de Pesquisa e Memória Pretos Novos - IPN}

\author{
Marco Antônio Teobaldo*
}

\section{Pretos Novos}

"Pretos novos" ou "boçais" era a denominação dada aos cativos recém-chegados da África, no Brasil,assim que desembarcavam no porto. Logo que eram vendidos ou aprendiam a o português passavam a ser chamados de "ladinos".

\section{Para entender a sua importância}

O Cemitério dos Pretos Novos, que funcionou durante os anos de 1769 a 1830, é a principal prova material e incontestável, encontrada até hoje, sobre a barbárie ocorrida no período mais intenso do tráfico de cativos africanos para o Brasil. Depois da descoberta fortuita feita pela família Guimarães dos Anjos, em 8 de janeiro de 1996, não há mais como admitir uma visão equivocada e romanceada sobre a escravidão de africanos e seus descendentes diretos no Brasil. Foram depositados no cemitério os restos mortais de dezenas de milhares de africanos, brutalmente retirados de sua terra natal e trazidos à força para o trabalho escravo. E igualmente bruta também era a forma como seus corpos foram despedaçados, queimados e espalhados pelo terreno, cobertos apenas com algumas pás de terra. Há indícios de que, dada a situação de descarte humano que apresentava o local, moradores daquela época que passavam pela Rua do Cemitério lançavam seu lixo doméstico: restos de comida e fragmentos de louças, cerâmicas e vidros.

Apesar de ser considerado o maior cemitério de escravizados deste gênero nas Américas, o terreno destinado aos sepultamentos era muito pequeno para tantos corpos. Os vestígios arqueológicos e históricos deste campo santo são testemunhos da ação violenta e cruel sofrida pelos africanos que não resistiram aos maus tratos da captura e viagem transatlântica. Este relato revelado pela historiografia e trazido à luz pela Arqueologia, repleto de desrespeito e dor, ainda é desconhecido por muitos, pois não é contado em todas as escolas e nem sequer é mencionado nos livros de história que

*Curador do IPN. Correspondência: Rua Pedro Ernesto, 32-34, Gambôa, Rio de Janeiro - RJ. CEP: $20220-350$. Email: <pretosnovos@pretosnovos.com.br>. 


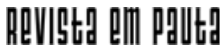

\} INSTITUTO DE PESQUISA E MEMÓRIA PRETOS NOVOS - TEOBALDO, M. A. \}

DOI: $10.12957 /$ REP.2018.39437

têm a escravidão como tema. Por isto, reafirma-se a importância deste Museu Memorial, no qual o Cemitério dos Pretos Novos se impõe como peça central para este debate.

\section{Origem}

G. W. Freireyss, o viajante alemão que descreveu o cemitério notou horrorizado que, neste local, a única marca da égide da Igreja era "uma pequena cruz de paus toscos mui velhos" fincada no centro do terreiro e cercada por ossadas insepultas.

Pelo lado do fundo está tudo aberto, dividido do quintal de uma propriedade vizinha por uma cerca de esteiras, e pelos outros dois lados com mui baixo muro de tijolos, e no meio uma pequena cruz de paus toscos mui velhos, e a terra do campo revolvida, e juncada de ossos mal queimados.

Os relatos de viajantes que estiveram pelo Rio de Janeiro, no século XIX, contam que o Cemitério dos Pretos Novos não passava de uma montanha de terra e de corpos despidos, em decomposição, que de tempos em tempos eram queimados e seus ossos quebrados e revirados à terra. Em 1853, o Caminho do Cemitério passa a se chamar Rua da Harmonia. Embora a existência do Cemitério dos Pretos Novos fosse conhecida de historiadores e da literatura sobre a cidade do Rio de Janeiro e sobre a escravidão no Brasil, sua localização tornou-se totalmente desconhecida por décadas até o ano de 1996, quando, por ocasião de uma obra realizada na fundação da casa, foram encontradas ossadas humanas a poucos centímetros de escavação.

A pesquisa inicial e a análise dos vestígios arqueológicos, feitas pelo Instituto de Arqueologia Brasileira (IAB), confirmaram que se tratava das ossadas depositadas no antigo Cemitério dos Pretos Novos. Após quatro anos de descaso do poder público, a Família Guimarães dos Anjos decide realizar por conta própria exposições itinerantes com o rico material encontrado nas escavações. Mas reconhecendo a importância do local para a história da cidade do Rio de Janeiro e para a divulgação da história dos Pretos Novos, percebem que ali deveria se tornar um espaço de visitação pública. No dia 20 de novembro de 2001 foi realizado o primeiro evento aberto ao público na residência. As atividades eram realizadas de maneira irregular e sem qualquer tipo de patrocínio ou subvenção, como por exemplo: os encontros com lideranças do movimento negro, rodas de samba e os bate-papos, que foram o embrião das oficinas realizadas atualmente.

No início, muito pouco se sabia sobre a história desses africanos sequestrados e trazidos para o Brasil. Os poucos registros encontrados sobre o tema falavam de números, mas muito pouco sobre a chegada e a vida do 


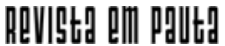

\} INSTITUTO DE PESQUISA E MEMÓRIA PRETOS NOVOS - TEOBALDO, M. A. \}

DOI: $10.12957 /$ REP.2018.39437

negro africano na colônia. Este fato é o que tem inspirado a trajetória do IPN a desenvolver atividades diversificadas voltadas à divulgação e à valorização da cultura negra, mesmo que no decorrer, o poder público tem se mantido praticamente omisso, com raros períodos em que se pode registrar o apoio parcial do governo. Este descaso contínuo se contrapõe aos diversos prêmios e moções de reconhecimento que a instituição tem recebido, desde a sua fundação. Entendemos que se faz urgente debatermos sobre o nosso passado, sobretudo o período escravocrata, que gerou feridas sociais que se negam a cicatrizarem. E não por acaso, o massacre dos povos africanos em terras brasileiras se estende até os dias de hoje aos seus descendentes.

DOI: 10.12957/rep.2018.39437



A Revista Em Pauta: Teoria Social e Realidade Contemporânea está licenciada com uma Licença Creative Commons Atribuição 4.0 Internacional. 


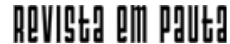

\} INSTITUTO DE PESQUISA E MEMÓRIA PRETOS NOVOS - TEOBALDO, M. A. \}

DOI: $10.12957 /$ REP.2018.39437

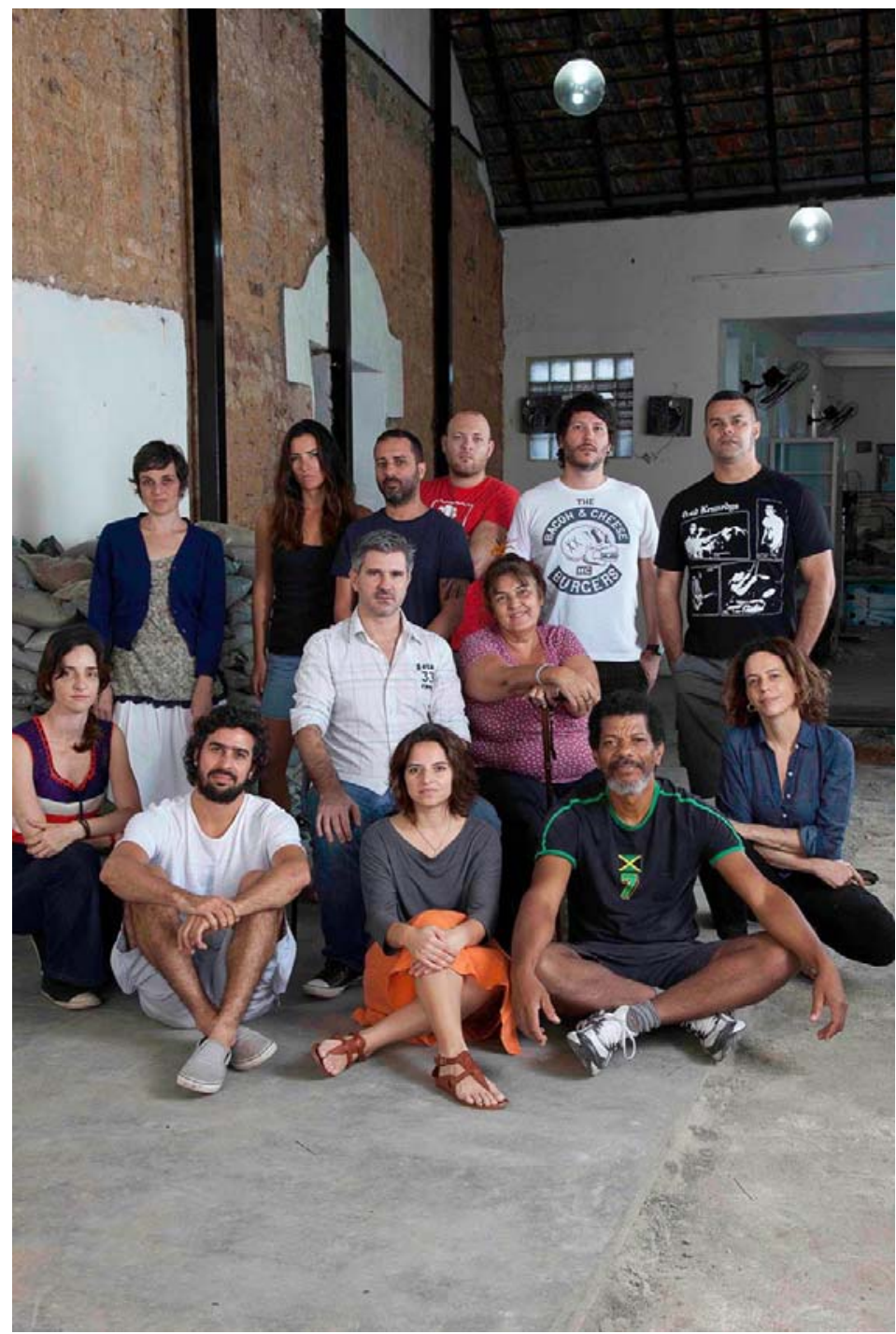

Galeria Pretos Novos, 2012. Primeiro grupo de artistas. 


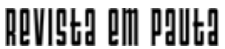

\} INSTITUTO DE PESQUISA E MEMÓRIA PRETOS NOVOS - TEOBALDO, M. A. \}

DOI: 10.12957/REP.2018.39437



Rosana Paulino. ASSENTAMENTO. IPN, 2014. 


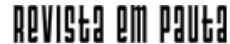

\} INSTITUTO DE PESQUISA E MEMÓRIA PRETOS NOVOS - TEOBALDO, M. A. \} DOI: $10.12957 /$ REP.2018.39437



Escavações arqueológicas durante obras do VLT, 2014. 


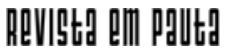

\} INSTITUTO DE PESQUISA E MEMÓRIA PRETOS NOVOS - TEOBALDO, M. A. \}

DOI: 10.12957/REP.2018.39437

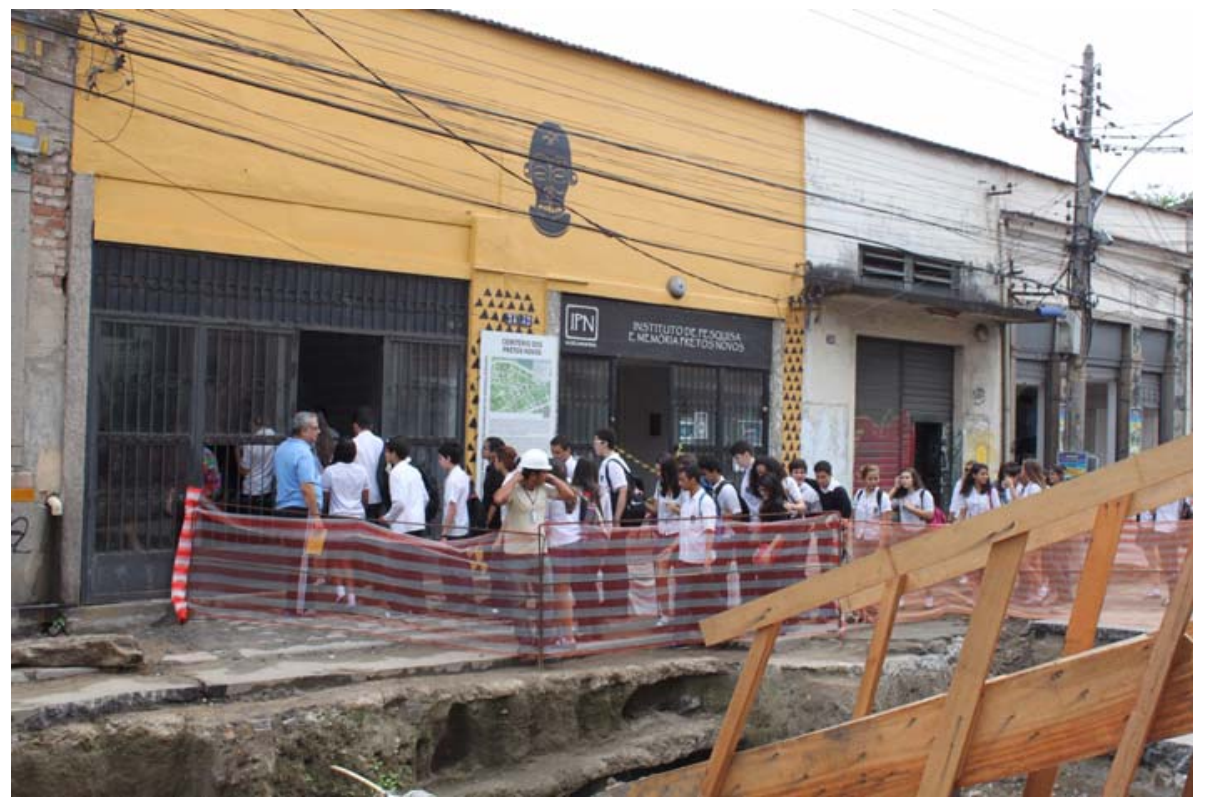

Arqueologia Rua I, 2014. 


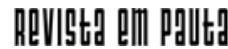

\} INSTITUTO DE PESQUISA E MEMÓRIA PRETOS NOVOS - TEOBALDO, M. A. \}

DOI: $10.12957 /$ REP.2018.39437

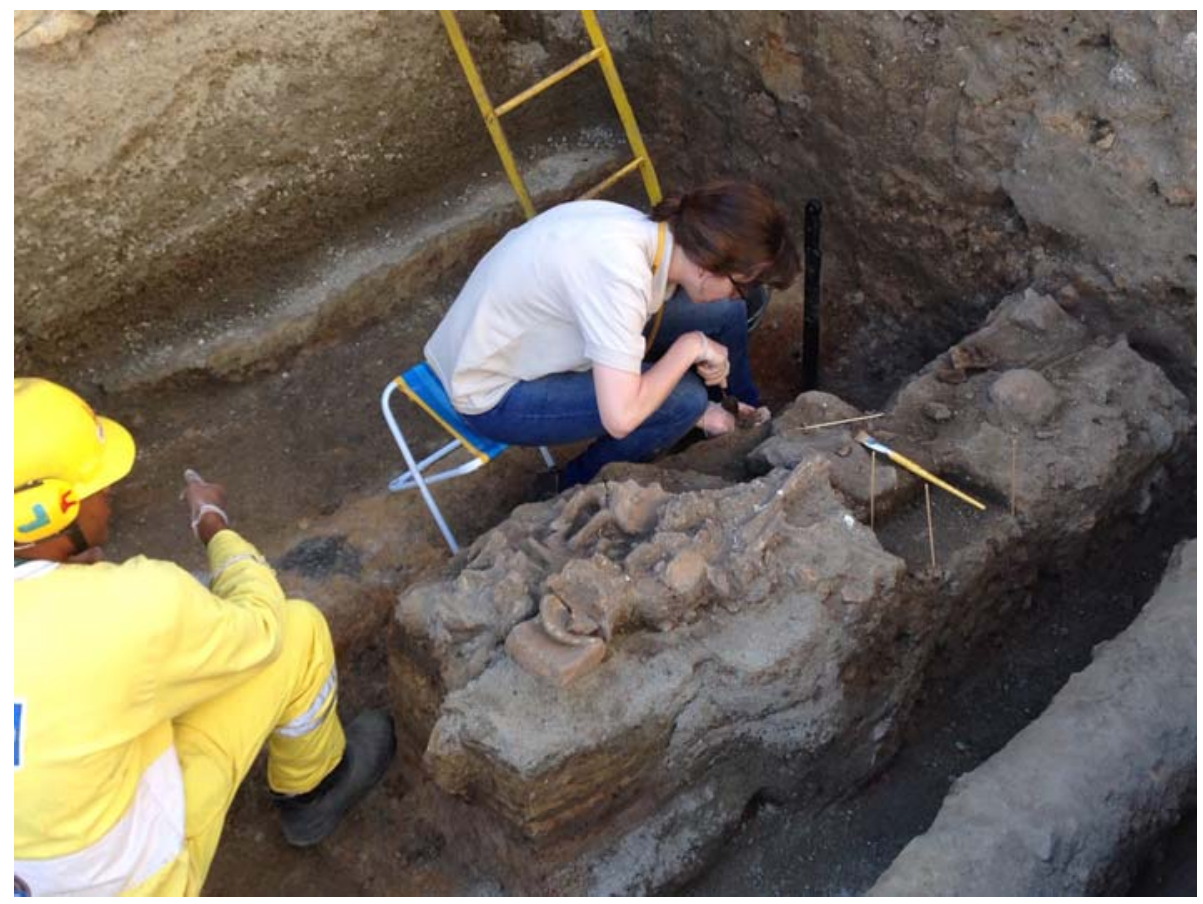

Escavações I, 2014. 


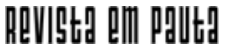

\} INSTITUTO DE PESQUISA E MEMÓRIA PRETOS NOVOS - TEOBALDO, M. A. \}

DOI: $10.12957 /$ REP.2018.39437

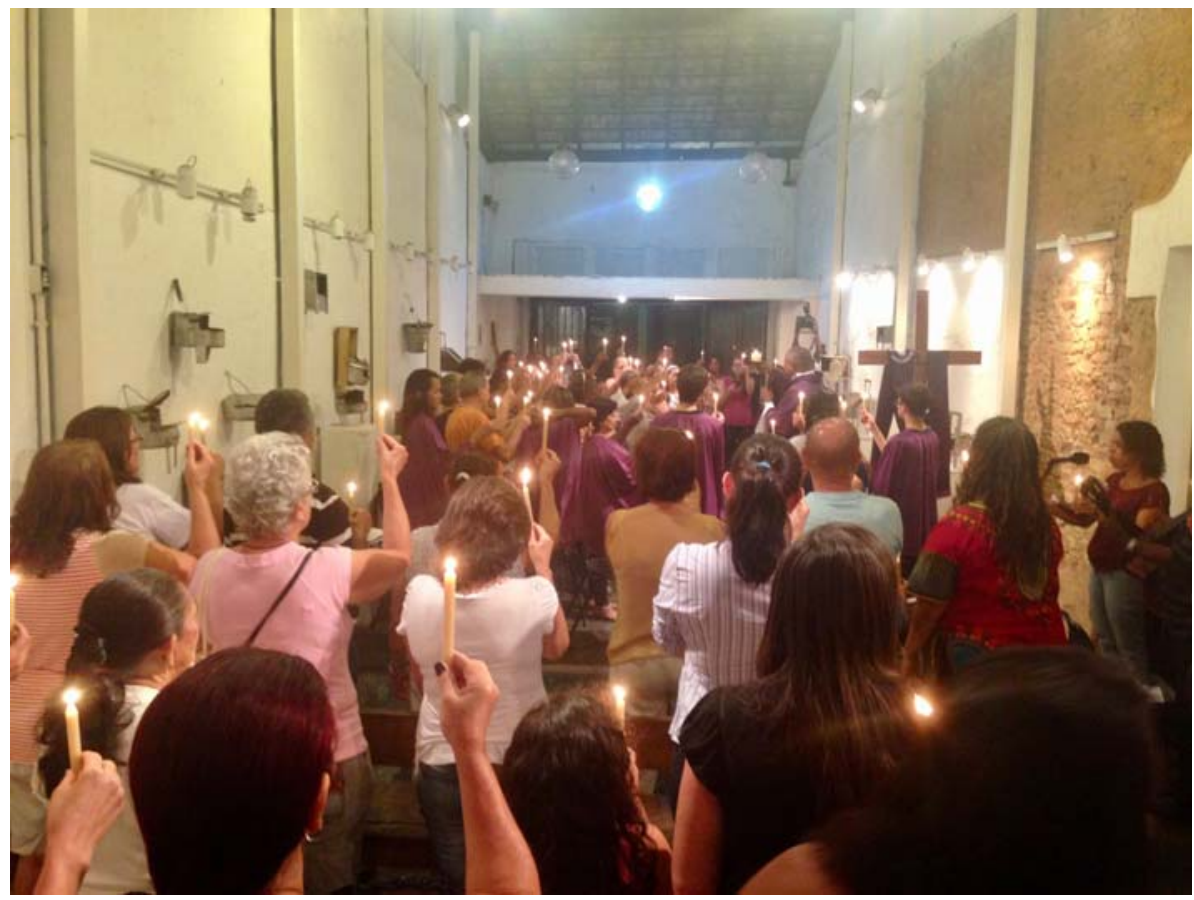

Tradicional Missa de Finados, IPN, 2015. 


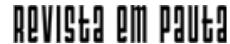

\} INSTITUTO DE PESQUISA E MEMÓRIA PRETOS NOVOS - TEOBALDO, M. A. \} DOI: $10.12957 /$ REP.2018.39437

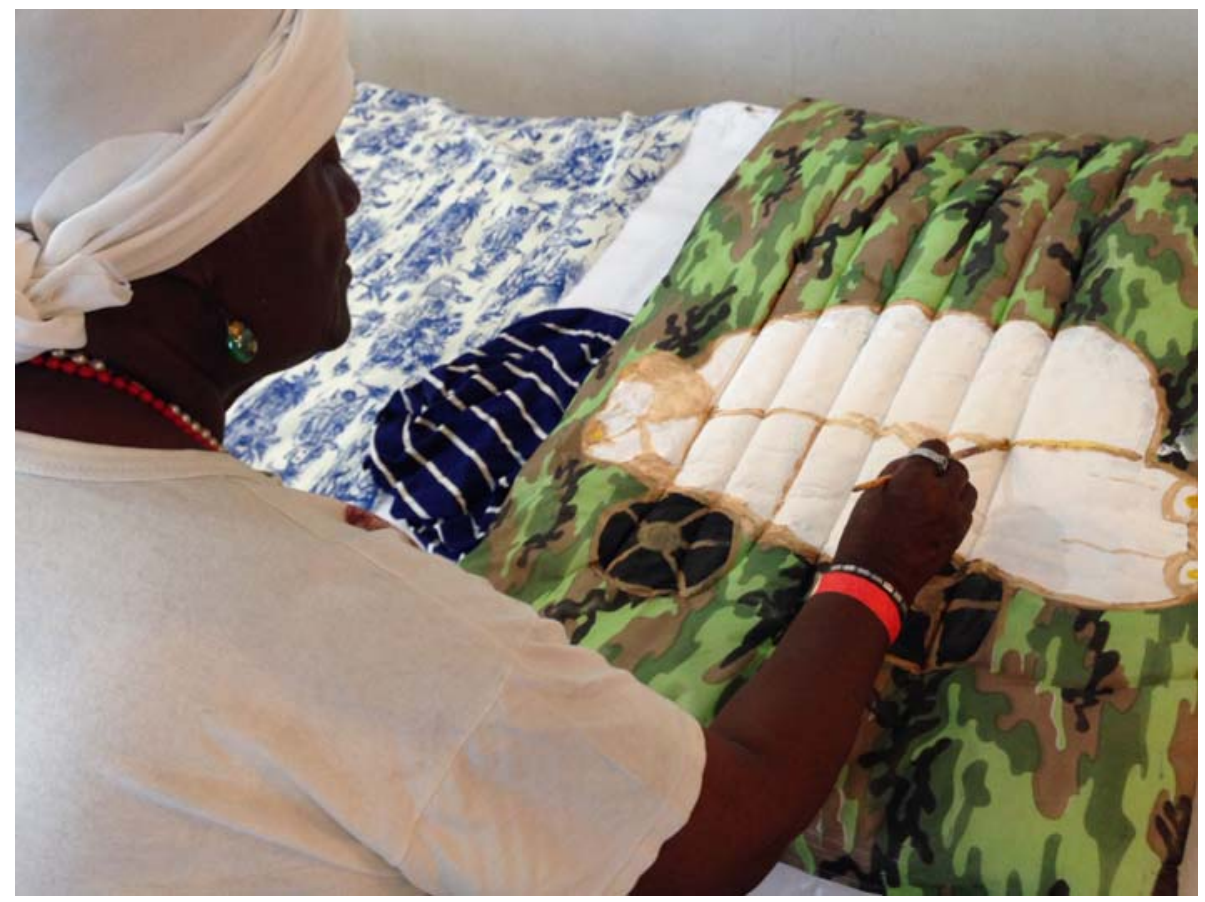

Tia Lúcia trabalhando I, 2015. 


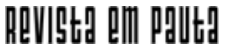

\} INSTITUTO DE PESQUISA E MEMÓRIA PRETOS NOVOS - TEOBALDO, M. A. \}

DOI: 10.12957/REP.2018.39437

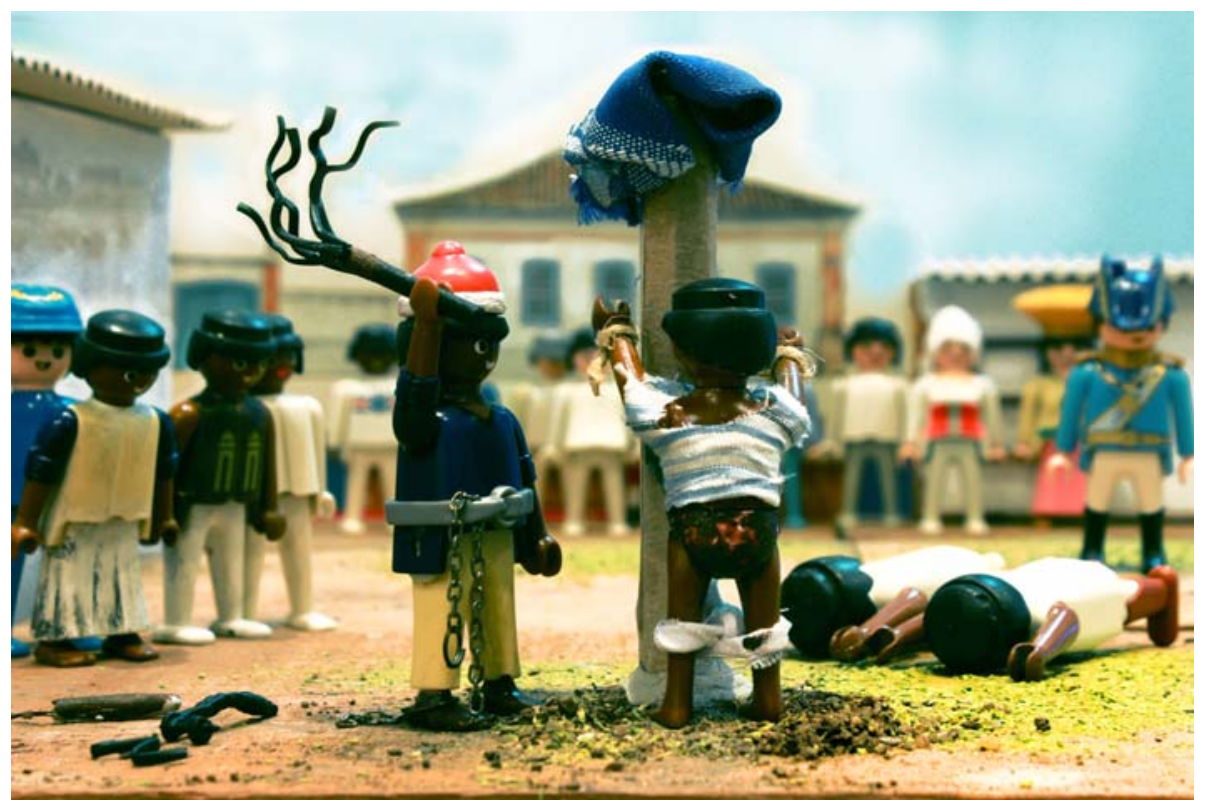

Heberth Sobral. Pelourinho. Exposição Estandartes, 2016. 


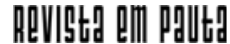

\} INSTITUTO DE PESQUISA E MEMÓRIA PRETOS NOVOS - TEOBALDO, M. A. \} DOI: $10.12957 /$ REP.2018.39437

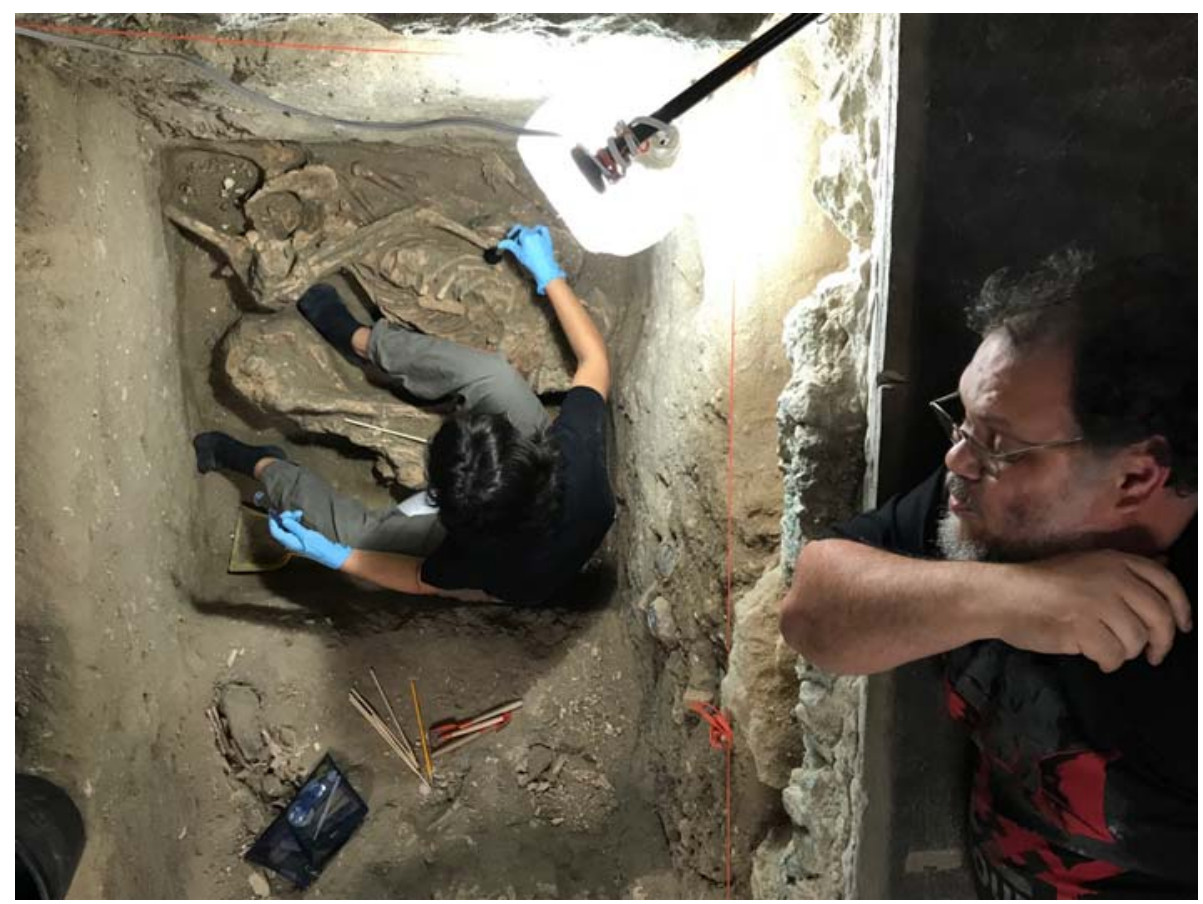

IV - Escavação 1, 2017. 


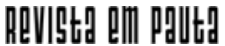

\} INSTITUTO DE PESQUISA E MEMÓRIA PRETOS NOVOS - TEOBALDO, M. A. \}

DOI: 10.12957/REP.2018.39437

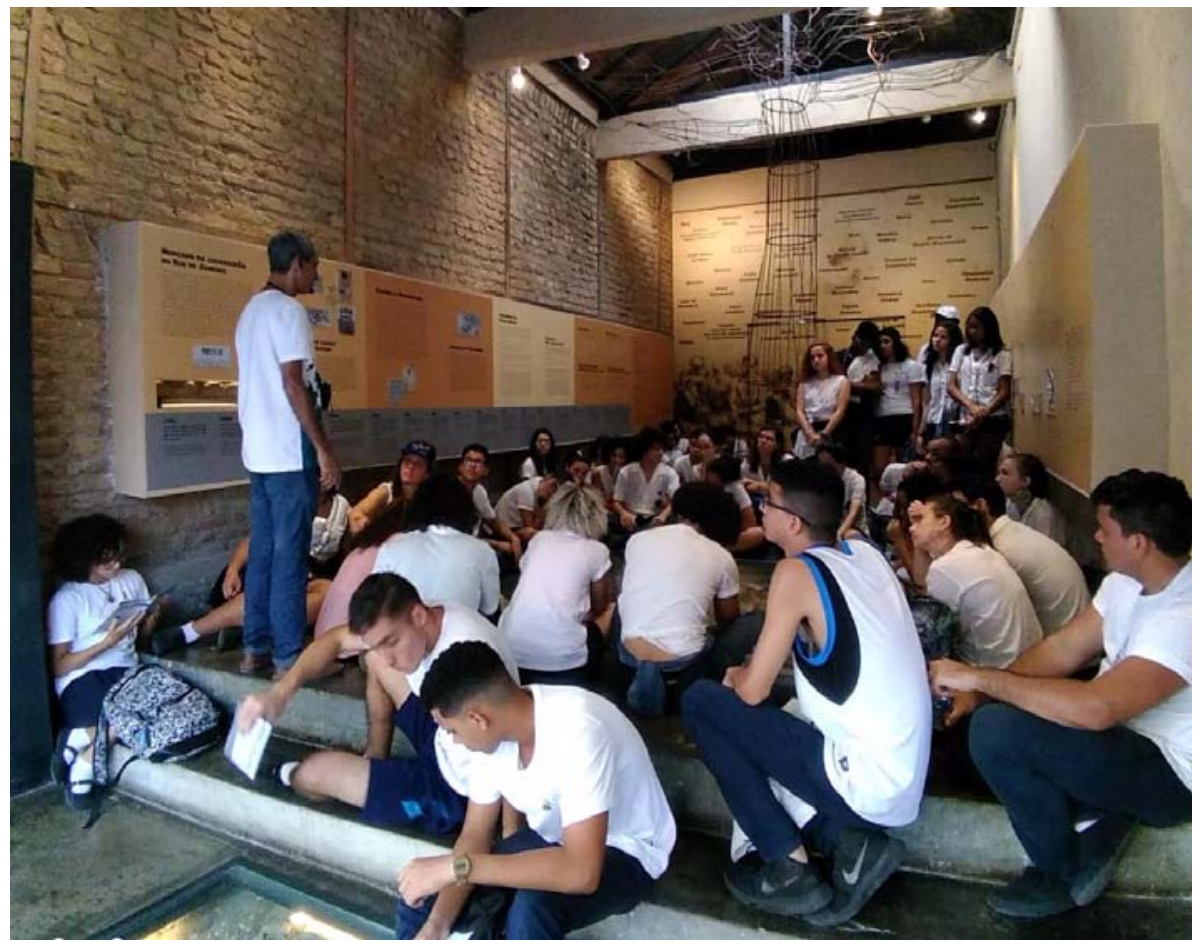

Memorial. Visitação, 2018. 


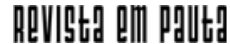

\} INSTITUTO DE PESQUISA E MEMÓRIA PRETOS NOVOS - TEOBALDO, M. A. \}

DOI: 10.12957/REP.2018.39437

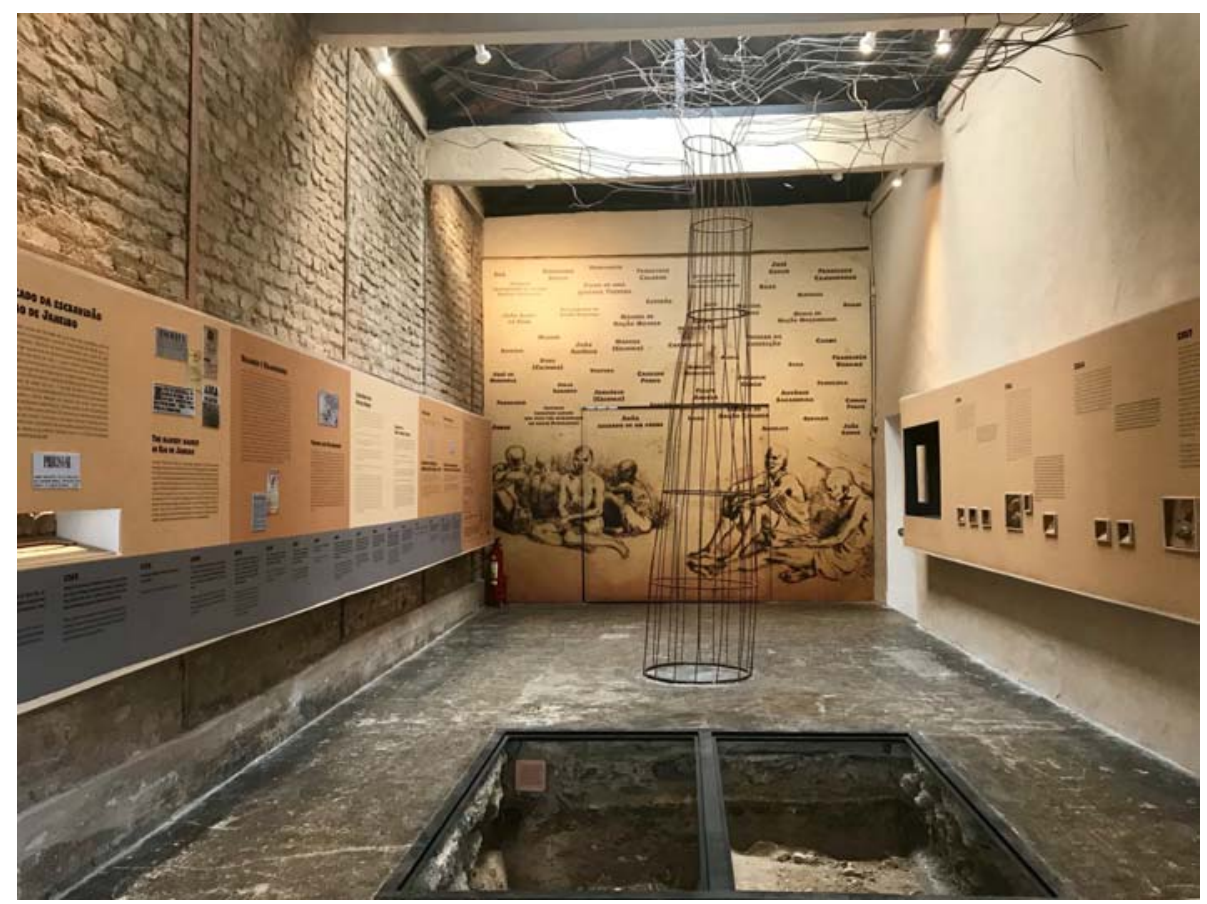

Vista geral do Museu, 2018. 